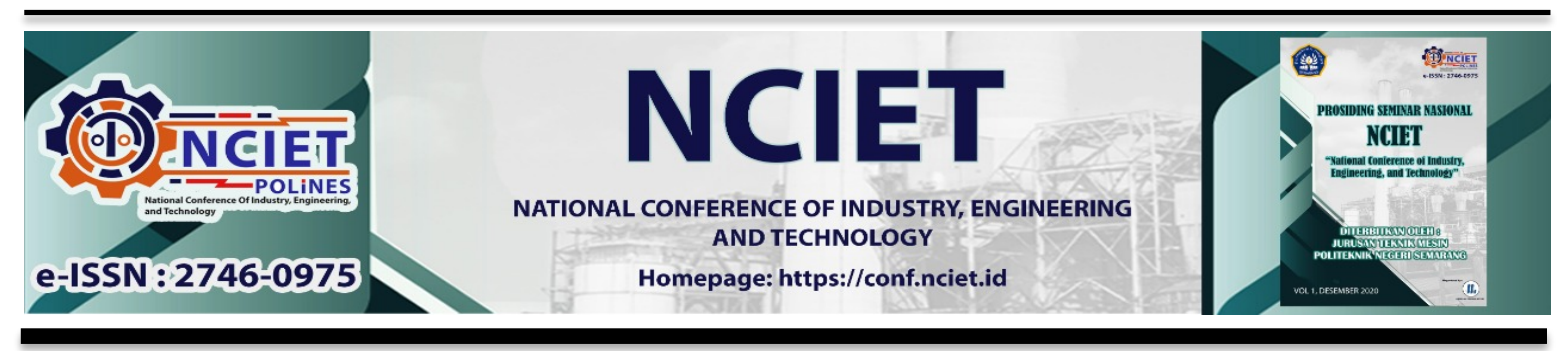

Prosiding Seminar Nasional NCIET Vol.1 (2020) B150-B161

$1^{\text {st }}$ National Conference of Industry, Engineering and Technology 2020,

Semarang, Indonesia.

\title{
SIMULASI KENDALI BOILER B-1102 PT. PETROKIMIA GRESIK BERBASIS DCS CENTUM VP
}

\author{
Hasna Nurhanifa Rosyadi*, Djiwo Harsono, Supriyono \\ Teknofisika Nuklir, STTN-BATAN \\ Jl. Babarsari PO BOX 6101 Ykbb, Yogyakarta, 55181 \\ *E-mail: hasnahanifa1@gmail.com
}

\begin{abstract}
Abstrak
Boiler B-1102 merupakan unit penyedia steam yang dikendalikan berbasis DCS oleh operator yang telah memahami proses-prosesnya. Boiler ini terdiri dari beberapa sistem yang saling berhubungan, salah satunya adalah sistem Steam \& Feed Water. Sistem ini bekerja dengan mengubah boiler feed water (BFW) menjadi steam melalui serangkaian proses pemanasan. Sistem kendali Boiler B-1102 di PT. Petrokimia Gresik sudah terhubung langsung dengan real plant, sehingga tidak memungkinkan bagi calon operator untuk belajar mengoperasikan kendali secara langsung. Oleh karena itu, dibuat simulasi kendali Boiler B-1102 pada sistem Steam \& Feed Water sebagai media pembelajaran dan pelatihan bagi calon operator. Penelitian ini dimulai dengan pembuatan project baru pada software Centum VP, pembuatan tampilan HMI, pemrograman DCS, dan pengujian simulasi melalui fitur test function pada software Centum VP. Sebagai visualisasi sistem sesungguhnya, telah dibuat 2 tampilan HMI, yaitu Main Window dan Trend Window. Pengujian indicator menampilkan hasil sesuai dengan input yang diberikan. Hasil pengujian proses analog control level air pada Steam Drum, suhu steam product, dan tekanan steam products dapat ditampilkan dalam perubahan nilai MV terhadap variasi PV dalam keadaan SV tetap, serta dapat diamati melalui trend. Hasil pengujian digital control berhasil menunjukkan nilai sesuai kondisi on dan off.
\end{abstract}

Kata Kunci: Simulasi; Sistem Kendali; Boiler B-1102; Steam \& Feed Water; Centum VP.

\section{PENDAHULUAN}

Salah satu unit penunjang yang berperan penting dalam proses produksi di Pabrik I PT. Petrokimia Gresik adalah Boiler B-1102 sebagai penyedia steam untuk keperluan proses di Unit Produksi Amonia, ZA I/III, dan PT. Petronika. Ketiganya kemudian disebut sebagai steam user. Proses produksi steam ini berlangsung terus-menerus dan dikendalikan menggunakan Disributed Control System (DCS). Sistem kendali pada Boiler B-1102 terbagi menjadi beberapa sub-sistem, salah satunya adalah sistem Steam \& Feed Water yang mengubah boiler feed water (BFW) menjadi uap kering (superheated steam) melalui proses pemanasan awal di bagian Economizer, pembakaran di bagian Steam Drum, pengubahan uap basah menjadi uap kering di bagian Superheater, penyesuaian suhu uap kering di bagian 
Desuperheater (DSH), dan penyesuaian tekanan agar dihasilkan steam akhir (steam product) yang siap untuk didistribusikan ke steam user.

Saat ini, sistem kendali DCS pada sistem Steam \& Feed Water di PT. Petrokimia sudah terhubung langsung ke real plant yang beroperasi, sehingga tidak memungkinkan bagi calon operator untuk belajar mengendalikan proses secara langsung melalui control room. Selain itu, untuk meningkatkan kualitas calon operator, diperlukan pemahaman tentang karakteristik proses yang dikendalikan melalui kegiatan training. Oleh karena itu, penyediaan simulator merupakan salah satu cara untuk mendukung proses training tanpa menganggu proses yang sedang berlangsung di real plant. Menurut Nashriyah (2017) simulator adalah alat atau media tambahan untuk melakukan simulasi dari sistem nyata (real plant), tetapi kerjanya agak lambat daripada keadaan sebenarnya. Penelitian ini menggunakan bantuan fitur test function pada software Centum VP untuk menyimulasikan pengendalian DCS sistem Steam \& Feed Water. Tujuan penelitian ini adalah membuat simulasi kendali Boiler B-1102 PT. Petrokimia Gresik khususnya pada sistem Steam \& Feed Water berbasis DCS Centum VP sebagai media pembelajaran dan pelatihan bagi calon operator.

\section{METODE PENELITIAN}

\section{Perancangan Sistem}

Perancangan sistem dilakukan dengan mengidentifikasi input/output yang digunakan dalam simulasi berdasarkan Piping \& Instrumentation Diagram (P\&ID) sistem Steam \& Feed Water. Sistem ini terdiri dari 12 pasang analog input/output, dan sepasang digital input/output. Selanjutnya, dilakukan pelabelan input/output untuk mempermudah penamaan dalam pemrograman DCS seperti pada Tabel 1.

Tabel 1. Pelabelan Input/Output

\begin{tabular}{clllll}
\hline No. & \multicolumn{1}{c}{ Input/Output } & Label & No. & \multicolumn{1}{c}{ Input/Output } & Label \\
\hline 1. & Flow Transmitter 600 & FT600 & 14. & Flow Indicator 600 & FI600 \\
2. & Temperature Transmitter 600 & TT600 & 15. & Temperature Indicator 600 & TI600 \\
3. & Pressure Transmitter 600 & PT600 & 16. & Pressure Indicator 600 & PI600 \\
4. & Level Transmitter 611A & LT611A & 17. & Flow Valve 60B & FV60B \\
5. & Temperature Transmitter 601 & TT601 & 18. & Temperature Indicator 601 & TI601 \\
6. & Temperature Transmitter 610 & TT610 & 19. & Temperature Indicator 610 & TI610 \\
7. & Pressure Transmitter 610 & PT610 & 20. & Pressure Indicator 610 & PI610 \\
8. & Temperature Transmitter 615 & TT615 & 21. & Temperature Indicator 615 & TI615 \\
9. & Flow Transmitter 610 & FT610 & 22. & Flow Indicator 610 & FI610 \\
10. & Temperature Transmitter 616 & TT616 & 23. & Temperature Valve 616 & TV616 \\
11. & Pressure Transmitter 611 & PT611 & 24. & Pressure Valve 611 & PV611 \\
12. & Flow Transmitter 616 & FT616 & 25. & Flow Indicator 616 & FI616 \\
13. & Digital Input Motor Operated & MOV610I & 26. & Motor Operated Valve 610 & MOV610O \\
& Valve 610 & & & & \\
\hline
\end{tabular}


Setelah mengetahui input/output, simulasi akan dijalankan berdasarkan skenario proses kerja sistem pada kondisi operasi normal seperti pada Gambar 1.

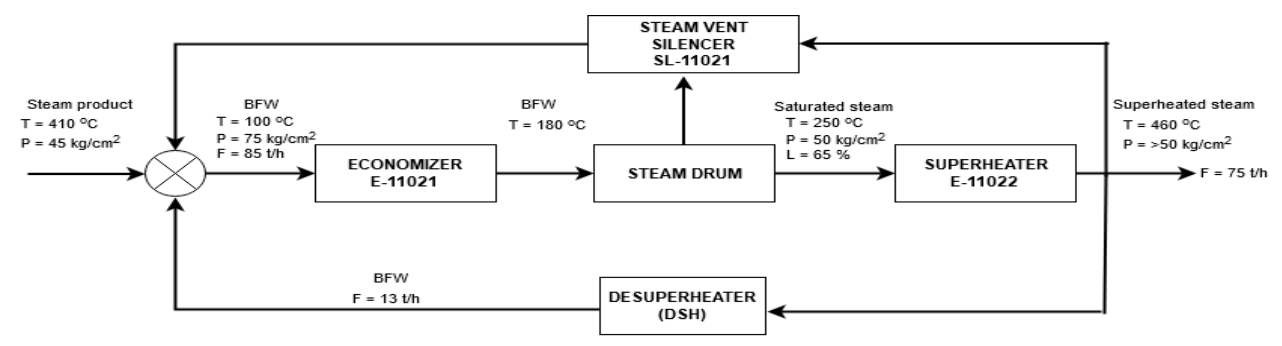

Gambar 1. Skenario Proses Kerja Sistem

Untuk mengasilkan steam, BFW dengan suhu $100{ }^{\circ} \mathrm{C}$ dan tekanan $75 \mathrm{~kg} / \mathrm{cm}^{2}$ dipompa ke Steam Drum melalui Economizer. Sebelum masuk ke Economizer, terdapat valve FV60B sebagai aktuator kendali level air pada Steam Drum. Keluaran Economizer berupa BFW dengan suhu $180^{\circ} \mathrm{C}$. Proses selanjutnya, BFW dialirkan menuju ke Steam Drum yang berisi pipa-pipa air (water tube). Proses ini disebut proses pembakaran sebenarnya, yaitu BFW dalam steam drum dibakar hingga mencapai suhu $250{ }^{\circ} \mathrm{C}$ dengan tekanan $50 \mathrm{~kg} / \mathrm{cm}^{2}$ oleh burner BR-11021 dan BR-11022. Hasil pembakaran di dalam steam drum ini menghasilkan saturated steam, kemudian masuk ke Superheater untuk dipanaskan kembali hingga mencapai suhu $460{ }^{\circ} \mathrm{C}$. Hal ini bertujuan untuk merubah saturated steam menjadi superheated steam. Selanjutnya, superheated steam ini dilewatkan ke Desuperheater (DSH) untuk menurunkan suhu superheated steam menjadi $410{ }^{\circ} \mathrm{C}$ dengan cara menyemprotkan kembali BFW melalui valve TV616 ke jalur steam product. Selain itu, diperlukan pula pengaturan tekanan steam melalui valve PV611. Pengaturan tekanan ini dilakukan oleh valve PV611 yang terhubung ke steam vent silencer SL-11021. Tekanan steam product yang dikehendaki steam user adalah $45 \mathrm{~kg} / \mathrm{cm}^{2}$. Keluaran steam akhir dengan suhu $410{ }^{\circ} \mathrm{C}$ dan tekanan $45 \mathrm{~kg} / \mathrm{cm}^{2}$ ini akan didistribusikan melalui HP header ke steam user.

\section{Pembuatan Project Baru pada Software Centum VP}

Pembuatan project baru dilakukan pada software Centum VP dengan mendaftarkan rincian project, tipe FCS, HIS, menambahkan node, dan mendaftarkan modul input/output untuk menghubungkan input/output ke Field Control Station (FCS) sebagai controller. Tipe FCS yang digunakan dalam penelitian ini adalah AFV10D. List input/output module yang digunakan dapat dilihat pada Tabel 2. 
Tabel 2. List Input/Output Module (IOM)

\begin{tabular}{clcl}
\hline Slot & Tipe IOM & No. Channel & \multicolumn{1}{c}{ Keterangan } \\
\hline 1 & AAI143-S50 & 16 & Analog Input \\
2 & AAI543-S50 & 16 & Analog Output \\
3 & ADV151-P10 & 32 & Digital Input \\
4 & ADV551-P03 & 32 & Digital Output \\
\hline
\end{tabular}

\section{Pembuatan HMI dan Pemrograman DCS}

Pembuatan Human Machine Interface (HMI) dilakukan menggunakan tools bernama Graphic Builder pada software Centum VP. Tampilan HMI yang dibuat pada penelitian ini terdiri dari dua window yaitu Main Window berupa Graphic, dan Trend Window berupa Trend Group.

Pembuatan program pada software Centum VP dilakukan dalam bentuk blok-blok yang memiliki fungsi tertentu (function block) di dalam Control Drawing Builder. Penelitian ini menggunakan 3 Control Drawing, yaitu DR0001 s/d DR0003. Diagram alir pemrograman dapat ditunjukkan pada Gambar 2.
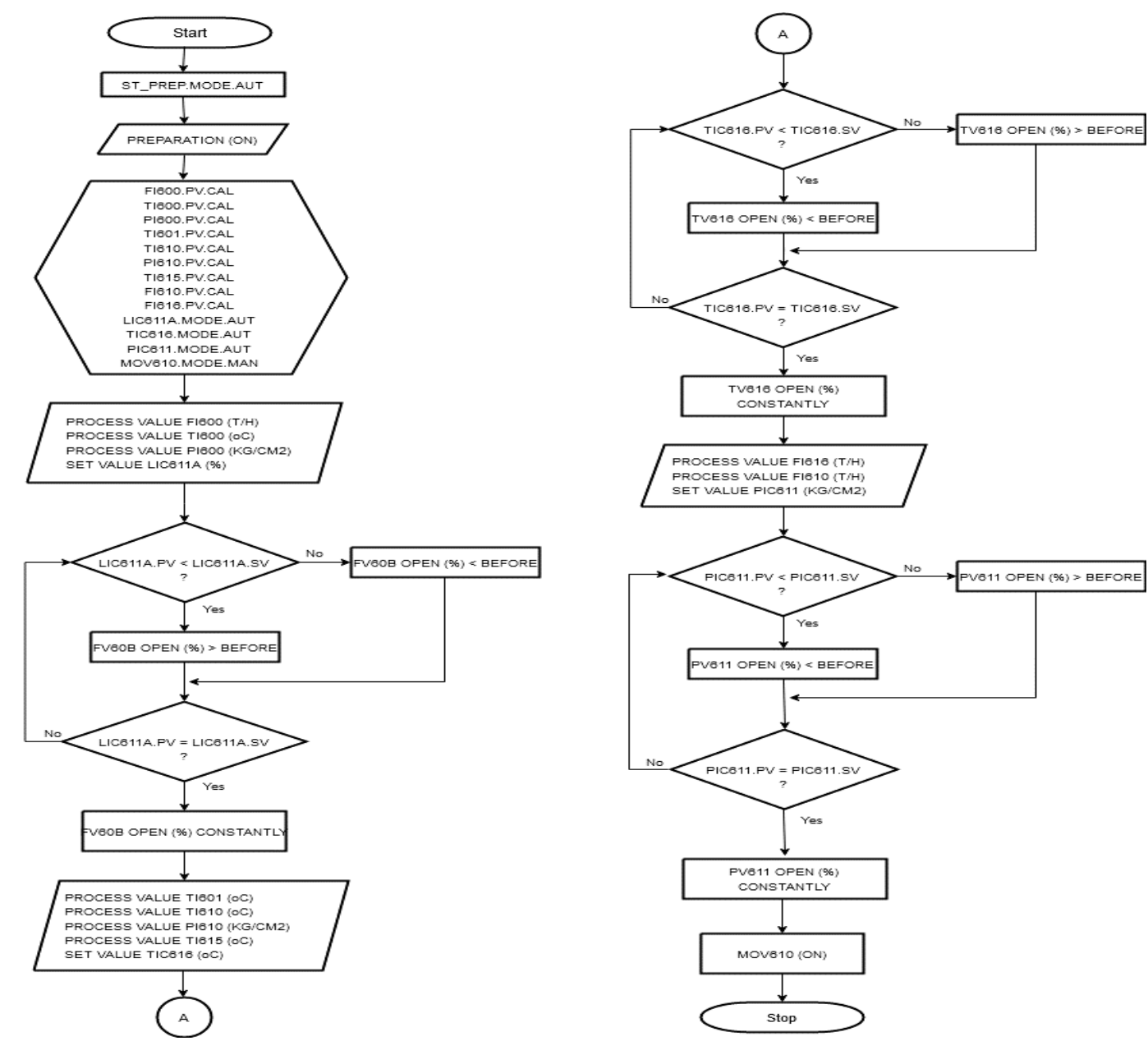

Gambar 2. Diagram Alir Pemrograman DCS 


\section{Pengujian Simulasi dengan Fitur Test Function}

Pengujian dilakukan untuk mengetahui apakah program simulasi yang dibuat pada software Centum VP telah bekerja sesuai skenario proses kerja sistem Steam \& Feed Water Boiler B-1102. Pengujian dilakukan dengan fitur test function pada software Centum VP dengan membandingkan hasil respon/output dengan input yang diberikan saat test function berjalan. Pengujian dibagi menjadi 3, yaitu :

\section{a. Pengujian Indicator : Flow, Temperature, dan Pressure}

Diisikan nilai Process Value (PV) pada indicator FI600, TI600, PI600, TI601, TI610, PI610, TI615, FI610, dan FI616 sebagai input pada faceplate. Kemudian hasil yang tertampil pada indicator HMI masing-masing diamati dan dicatat sebagai output.

\section{b. Pengujian Analog Control : Level, Pressure, Temperature}

Diisikan nilai Set Value (SV) pada LIC611A, TIC616, dan PIC611 sebagai input, sesuai nilai operasi normal pada Tabel 3.

Tabel 3. SV Pengujian Analog Control

\begin{tabular}{lc}
\hline \multicolumn{1}{c}{ Parameter } & Nilai SV \\
\hline LIC611A & $65 \%$ \\
TIC616 & $410^{\circ} \mathrm{C}$ \\
PIC611 & $45 \mathrm{~kg} / \mathrm{cm}^{2}$ \\
\hline
\end{tabular}

Selanjutnya, persentase bukaan valve FV60B, TV616, dan PV611 diamati berturut-turut sebagai nilai Manipulated Value (MV). Kemudian, nilai PV divariasikan pada keadaan di atas dan di bawah SV yang telah ditetapkan pada Tabel 3. Nilai MV masing-masing diamati kembali perubahannya sebagai output.

\section{c. Pengujian Digital Control}

Pengujian dilakukan dengan melakukan double-click pada objek MOV610 sebagai input. Kemudian diamati respon perubahan warna objek tersebut pada keadaan $O n$ dan Off sebagai nilai output.

\section{HASIL DAN PEMBAHASAN}

\section{Hasil Tampilan HMI}

Pembuatan HMI diperlukan dalam proses simulasi sebagai antarmuka antara operator dengan sistem yang dikendalikan. Hasil pembuatan HMI bagian Main Window dapat dilihat seperti pada Gambar 3. 


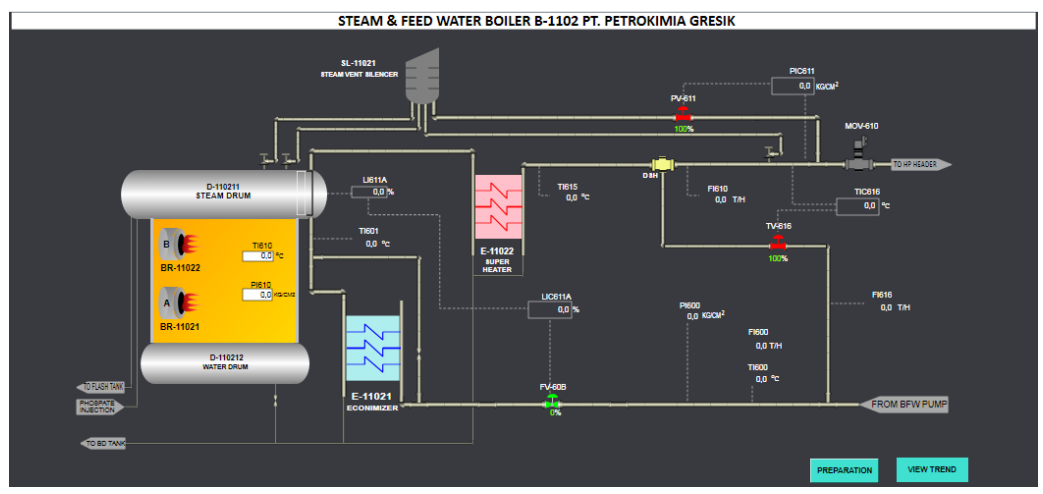

Gambar 3. Tampilan HMI pada Main Window

Main window terdiri dari gambaran field instrument sistem Steam \& Feed Water Boiler B-1102 yang dikendalikan, dan dua buah push button. Push button "PREPARATION" digunakan untuk menjalankan proses preparasi dengan mengubah kondisi indicator dari keadaan normal AUT menjadi CAL, mengubah mode operasi analog control dari keadaan normal mode MAN menjadi AUT, dan digital control dari keadaan normat mode AUT menjadi MAN. Selain itu, terdapat push button "VIEW TREND" yang digunakan untuk menuju ke tampilan HMI Trend Window. Tampilan Trend Window ditunjukkan pada Gambar 4.

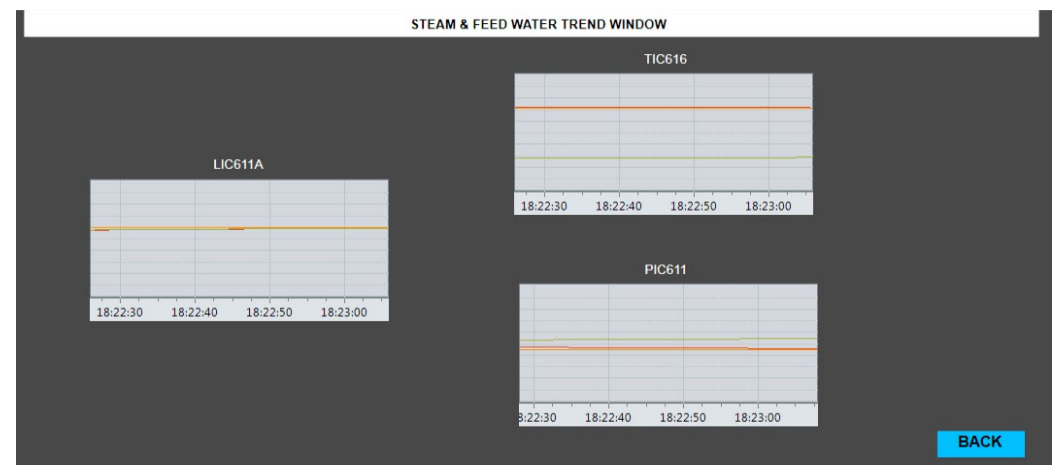

Gambar 4. Tampilan HMI pada Trend Window

Melalui Trend Window ini, trend data pengendalian LIC611A, TIC616, dan PIC611 dapat diamati perubahannya terhadap waktu secara kontinyu. Selain itu, pada Trend Window ini terdapat tombol "BACK" yang digunakan untuk kembali menuju ke tampilan HMI Main Window.

\section{Hasil Pengujian Simulasi}

Pengujian hasil simulasi penelitian ini dilakukan menggunakan fitur test function pada software Centum VP. Fitur tersebut digunakan untuk melakukan virtual test melalui 
personal computer (PC) tanpa harus terhubung secara fisik ke FCS. Pengujian ini dibagi menjadi tiga yaitu, pengujian indicator, analog control, digital control. Nilai yang diamati dalam pengujian diantaranya adalah nilai SV, PV, dan MV.

Pengujian indicator nilai laju aliran BFW menggunakan FT600 sebagai input dan FI600 sebagai output. Hasil pengujian FI600 dapat dilihat hasilnya pada Tabel 4.

Tabel 4. Hasil Pengujian Indicator Flow BFW (FI600)

\begin{tabular}{cccc}
\hline $\begin{array}{c}\text { Indicator } \\
\text { (satuan) }\end{array}$ & $\begin{array}{c}\text { Pengujian } \\
\text { ke- }\end{array}$ & $\begin{array}{c}\text { Input } \mathrm{PV} \\
\text { pada Faceplate }\end{array}$ & $\begin{array}{c}\text { Output } \mathrm{PV} \\
\text { pada HMI }\end{array}$ \\
\hline & 1 & 75 & 75 \\
FI600 & 2 & 80 & 80 \\
$(\mathrm{~T} / \mathrm{H})$ & 3 & 85 & 85 \\
& 4 & 90 & 90 \\
& 5 & 95 & 95 \\
\hline
\end{tabular}

Hasil pengujian indicator nilai suhu BFW dapat dilihat pada Tabel 5. Indicator ini menggunakan TT600 sebagai input dan TI600 sebagai output.

Tabel 5. Hasil Pengujian Indicator Temperature BFW (TI600)

\begin{tabular}{cccc}
\hline $\begin{array}{c}\text { Indicator } \\
\text { (satuan) }\end{array}$ & $\begin{array}{c}\text { Pengujian } \\
\text { ke- }\end{array}$ & $\begin{array}{c}\text { Input } \mathrm{PV} \\
\text { pada Faceplate }\end{array}$ & $\begin{array}{c}\text { Output PV } \\
\text { pada HMI }\end{array}$ \\
\hline & 1 & 90 & 90 \\
TT600 & 2 & 95 & 95 \\
$\left({ }^{\circ} \mathrm{C}\right)$ & 3 & 100 & 100 \\
& 4 & 105 & 105 \\
& 5 & 110 & 110 \\
\hline
\end{tabular}

Pengujian indicator nilai tekanan BFW menggunakan PT600 sebagai input dan PI600 sebagai output. Hasil pengujian PI600 dapat dilihat hasilnya pada Tabel 6.

Tabel 6. Hasil Pengujian Indicator Pressure BFW (PI600)

\begin{tabular}{cccc}
\hline $\begin{array}{c}\text { Indicator } \\
\text { (satuan) }\end{array}$ & $\begin{array}{c}\text { Pengujian } \\
\text { ke- }\end{array}$ & $\begin{array}{c}\text { Input PV } \\
\text { pada Faceplate }\end{array}$ & $\begin{array}{c}\text { Output PV } \\
\text { pada HMI }\end{array}$ \\
\hline & 1 & 65 & 65 \\
PI600 & 2 & 70 & 70 \\
$\left(\mathrm{~kg} / \mathrm{cm}^{2}\right)$ & 3 & 75 & 75 \\
& 4 & 80 & 80 \\
& 5 & 85 & 85 \\
\hline
\end{tabular}

Hasil pengujian indicator nilai suhu BFW keluaran Economizer dapat dilihat pada Tabel 7. Indicator ini menggunakan TT601 sebagai input dan TI601 sebagai output.

Tabel 7. Hasil Pengujian Indicator Temperature BFW Keluaran Economizer (TI601)

\begin{tabular}{cccc}
\hline $\begin{array}{c}\text { Indicator } \\
\text { (satuan) }\end{array}$ & $\begin{array}{c}\text { Pengujian } \\
\text { ke- }\end{array}$ & Input $\mathrm{PV}$ & Output $\mathrm{PV}$ \\
pada Faceplate & pada HMI \\
\hline
\end{tabular}




\begin{tabular}{cccc}
\hline & 1 & 170 & 170 \\
TI601 & 2 & 175 & 175 \\
$\left({ }^{\circ} \mathrm{C}\right)$ & 3 & 180 & 180 \\
& 4 & 185 & 185 \\
& 5 & 190 & 190 \\
\hline
\end{tabular}

Pengujian indicator suhu saturated steam hasil pembakaran pada bagian Steam Drum menggunakan TT610 sebagai input dan TI610 sebagai output. Hasil pengujian TI610 dapat dilihat hasilnya pada Tabel 8.

Tabel 8. Hasil Pengujian Indicator Temperature Saturated Steam (TI610)

\begin{tabular}{cccc}
\hline $\begin{array}{c}\text { Indicator } \\
\text { (satuan) }\end{array}$ & $\begin{array}{c}\text { Pengujian } \\
\text { ke- }\end{array}$ & $\begin{array}{c}\text { Input PV } \\
\text { pada Faceplate }\end{array}$ & $\begin{array}{c}\text { Output PV } \\
\text { pada HMI }\end{array}$ \\
\hline & 1 & 240 & 240 \\
TI610 & 2 & 245 & 245 \\
$\left({ }^{\circ} \mathrm{C}\right)$ & 3 & 250 & 250 \\
& 4 & 255 & 255 \\
& 5 & 260 & 260 \\
\hline
\end{tabular}

Pengujian indicator nilai tekanan saturated steam menggunakan PT610 sebagai input dan PI610 sebagai output. Hasil pengujian PI610 dapat dilihat hasilnya pada Tabel 9.

Tabel 9. Hasil Pengujian Indicator Pressure Saturated Steam (PI610)

\begin{tabular}{cccc}
\hline $\begin{array}{c}\text { Indicator } \\
\text { (satuan) }\end{array}$ & $\begin{array}{c}\text { Pengujian } \\
\text { ke- }\end{array}$ & $\begin{array}{c}\text { Input } \mathrm{PV} \\
\text { pada Faceplate }\end{array}$ & $\begin{array}{c}\text { Output } \mathrm{PV} \\
\text { pada HMI }\end{array}$ \\
\hline & 1 & 40 & 40 \\
PI610 & 2 & 45 & 45 \\
$\left(\mathrm{~kg} / \mathrm{cm}^{2}\right)$ & 3 & 50 & 50 \\
& 4 & 55 & 55 \\
& 5 & 60 & 60 \\
\hline
\end{tabular}

Hasil pengujian indicator nilai suhu superheated steam dapat dilihat pada Tabel 10 . Indicator ini menggunakan TT615 sebagai input dan TI615 sebagai output.

Tabel 10. Hasil Pengujian Indicator Temperature Superheated Steam (TI615)

\begin{tabular}{cccc}
\hline $\begin{array}{c}\text { Indicator } \\
\text { (satuan) }\end{array}$ & $\begin{array}{c}\text { Pengujian } \\
\text { ke- }\end{array}$ & $\begin{array}{c}\text { Input PV } \\
\text { pada Faceplate }\end{array}$ & $\begin{array}{c}\text { Output PV } \\
\text { pada HMI }\end{array}$ \\
\hline & 1 & 450 & 450 \\
$\mathrm{TI} 615$ & 2 & 455 & 455 \\
$\left({ }^{\circ} \mathrm{C}\right)$ & 3 & 460 & 460 \\
& 4 & 465 & 465 \\
& 5 & 470 & 470 \\
\hline
\end{tabular}

Pengujian indicator nilai laju aliran steam product menggunakan FT610 sebagai input dan FI610 sebagai output. Hasil pengujian FI610 dapat dilihat hasilnya pada Tabel 11. 
Tabel 11. Hasil Pengujian Indicator Flow Steam Product (FI610)

\begin{tabular}{cccc}
\hline $\begin{array}{c}\text { Indicator } \\
\text { (satuan) }\end{array}$ & $\begin{array}{c}\text { Pengujian } \\
\text { ke- }\end{array}$ & $\begin{array}{c}\text { Input } \mathrm{PV} \\
\text { pada Faceplate }\end{array}$ & $\begin{array}{c}\text { Output } \mathrm{PV} \\
\text { pada HMI }\end{array}$ \\
\hline & 1 & 65 & 65 \\
$\mathrm{FI} 610$ & 2 & 70 & 70 \\
$(\mathrm{~T} / \mathrm{H})$ & 3 & 75 & 75 \\
& 4 & 80 & 80 \\
& 5 & 80 & 80 \\
\hline
\end{tabular}

Hasil pengujian indicator laju aliran BFW menuju Desuperheater (DSH) dapat dilihat pada Tabel 12. Indicator ini menggunakan FT616 sebagai input dan FI616 sebagai output.

Tabel 12. Hasil Pengujian Indicator Flow BFW ke DSH (FI616)

\begin{tabular}{cccc}
\hline $\begin{array}{c}\text { Indicator } \\
\text { (satuan) }\end{array}$ & $\begin{array}{c}\text { Pengujian } \\
\text { ke- }\end{array}$ & $\begin{array}{c}\text { Input PV } \\
\text { pada Faceplate }\end{array}$ & $\begin{array}{c}\text { Output PV } \\
\text { pada HMI }\end{array}$ \\
\hline & 1 & 3 & 3 \\
FI616 & 2 & 8 & 8 \\
$(\mathrm{~T} / \mathrm{H})$ & 3 & 13 & 13 \\
& 4 & 18 & 18 \\
& 5 & 23 & 23 \\
\hline
\end{tabular}

Hasil pengujian indicator pada Tabel 4 s/d Tabel 12 dikatakan sesuai, karena memiliki lenearitas penunjukkan nilai output terhadap input. Artinya, hasil masing-masing pada HMI tidak memiliki penyimpangan terhadap nilai input yang dimasukkan pada faceplate.

Selanjutnya, pengujian analog control dapat ditampilkan dalam perubahan nilai MV terhadap variasi PV dalam keadaan SV yang telah ditetapkan, serta dapat diamati proses pengendaliannya melalui trend.

Pengujian analog control LIC611A sebagai pengendali level air dalam Steam Drum dengan jenis reverse action dengan nilai SV 65\% dapat dilihat hasilnya pada Gambar 5. Input LIC611A berasal dari pembacaan LT611A (nilai PV), kemudian diolah oleh controller untuk menghasilkan sinyal aksi kepada aktuator valve FV60B (nilai MV).

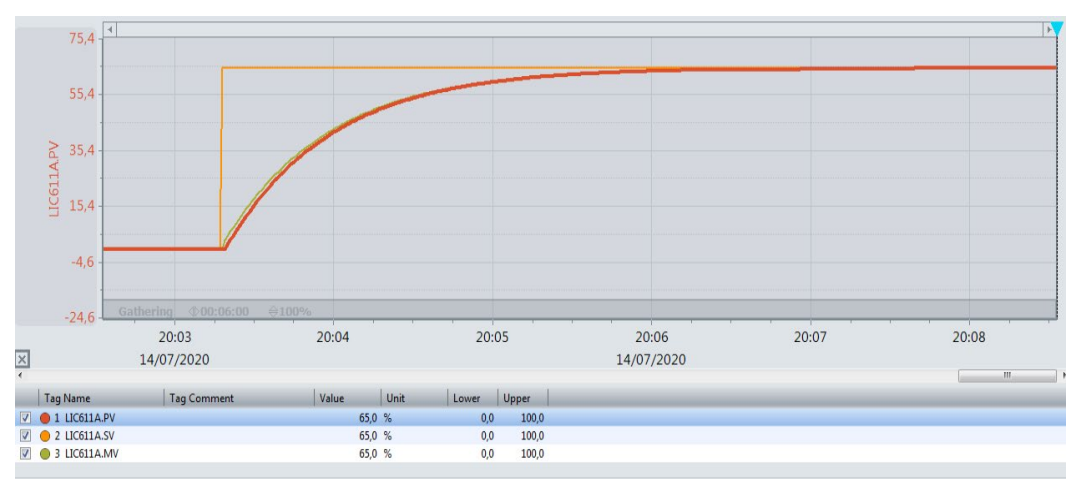

Gambar 5. Trend Respon Pengendalian pada LIC611A 
Pengujian variasi nilai PV dengan SV tetap sebesar 65\% mempengaruhi persentase bukaan valve FV60B seperti pada Tabel 13.

Tabel 12. Hasil Pengujian Analog Control Level Air pada Steam Drum (LIC611A)

\begin{tabular}{cccc}
\hline $\begin{array}{c}\text { Pengujian } \\
\text { ke- }\end{array}$ & SV (\%) & PV (\%) & MV (\%) \\
\hline 1 & 65 & 55,6 & 56 \\
2 & 65 & 60,0 & 60 \\
3 & 65 & 65,0 & 65 \\
4 & 65 & 70,0 & 71 \\
5 & 65 & 75,7 & 76 \\
\hline
\end{tabular}

Hasil pengujian ini menunjukkan karakteristik proses yang terjadi pada LIC611A bahwa ketika nilai PV melebihi SV, maka terjadi penurunan persentase bukaan MV untuk mengurangi air yang masuk ke steam drum agar tidak terjadi kelebihan level. Sebaliknya, jika PV kurang dari SV, maka persentase bukaan MV mengalami peningkatan sebagai upaya untuk menambah suplai air yang masuk ke steam drum agar mencapai nilai SV.

Pengujian analog control TIC616 sebagai pengendali temperature steam product memperoleh input dari pembacaan TT616 (nilai PV) yang diolah oleh controller untuk menggerakkan aktuator valve TV616 dalam bentuk persentase bukaan (nilai MV). Trend TIC 616 dengan SV sebesar $410^{\circ} \mathrm{C}$ dapat dilihat pada Gambar 6 .

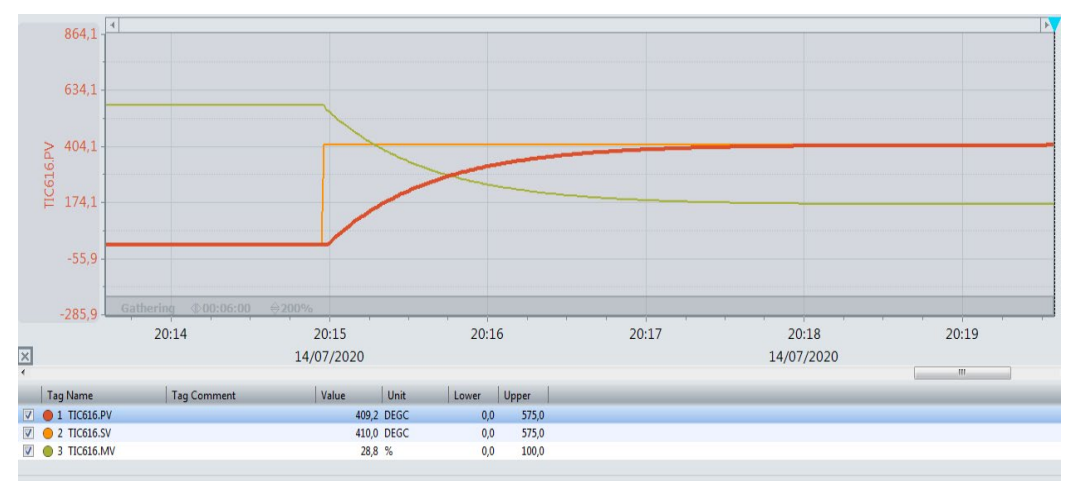

Gambar 6. Trend Respon Pengendalian pada TIC616

Pengujian variasi nilai PV dengan SV tetap sebesar $410{ }^{\circ} \mathrm{C}$ mempengaruhi persentase bukaan valve TV616 seperti pada Tabel 14.

Berdasarkan hasil variasi pada Tabel 14, peningkatan persentase bukaan MV pada TIC616 bertujuan untuk menyemprotkan lebih banyak BFW dari jalur pipa awal sistem menuju ke jalur pipa steam product agar suhunya menurun sesuai nilai SV, sedangkan penurunan bukaan MV adalah upaya agar suhu steam product masih bisa meningkat sesuai SV dengan mengurangi BFW yang disemprotkan dari jalur pipa awal sistem. 
Tabel 14. Hasil Pengujian Analog Control Suhu Steam Product (TIC616)

\begin{tabular}{cccc}
\hline $\begin{array}{c}\text { Pengujian } \\
\text { ke- }\end{array}$ & SV $\left({ }^{\circ} \mathrm{C}\right)$ & $\mathrm{PV}\left({ }^{\circ} \mathrm{C}\right)$ & $\mathrm{MV}(\%)$ \\
\hline 1 & 410 & 350,7 & 39 \\
2 & 410 & 400,5 & 30 \\
3 & 410 & 410,0 & 29 \\
4 & 410 & 450,9 & 22 \\
5 & 410 & 504,2 & 12 \\
\hline
\end{tabular}

Pengujian analog control PIC611 sebagai pengendali pressure steam product dengan nilai SV sebesar $45 \mathrm{~kg} / \mathrm{cm}^{2}$ dapat dilihat pada Gambar 7. Input PIC611 berasal dari pembacaan PT611 (nilai PV), kemudian diolah oleh controller untuk menghasilkan sinyal aksi kepada aktuator valve PV611 (nilai MV). Pengujian variasi nilai PV dengan SV tetap sebesar $45 \mathrm{~kg} / \mathrm{cm}^{2}$ mempengaruhi persentase bukaan valve PV611 seperti pada Tabel 15 .

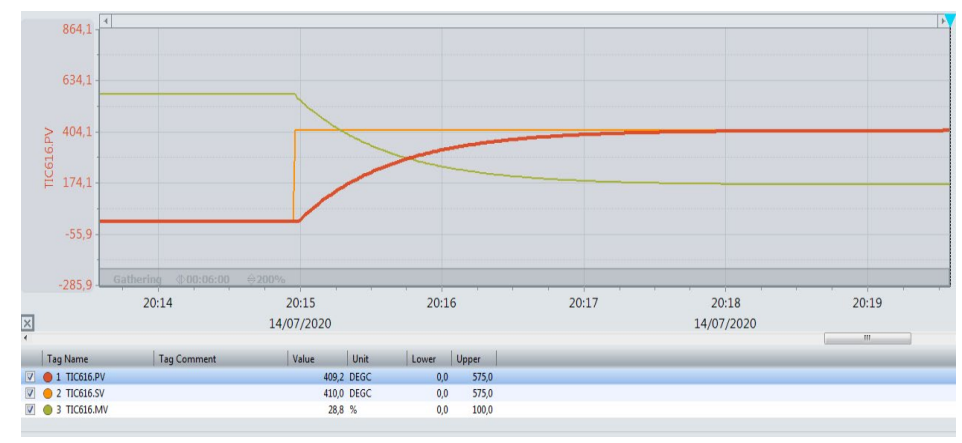

Gambar 6. Trend Respon Pengendalian pada PIC611

Tabel 15. Hasil Pengujian Analog Control Tekanan Steam Product (PIC611)

\begin{tabular}{cccc}
\hline $\begin{array}{c}\text { Pengujian } \\
\text { ke- }\end{array}$ & $\mathrm{SV}\left(\mathrm{kg} / \mathrm{cm}^{2}\right)$ & $\mathrm{PV}\left(\mathrm{kg} / \mathrm{cm}^{2}\right)$ & $\mathrm{MV}\left(\mathrm{kg} / \mathrm{cm}^{2}\right)$ \\
\hline 1 & 45 & 30,2 & 70 \\
2 & 45 & 35,1 & 65 \\
3 & 45 & 45,0 & 55 \\
4 & 45 & 50,6 & 49 \\
5 & 45 & 55,8 & 44 \\
\hline
\end{tabular}

Pada hasil pengujian variasi PV di PIC611, peningkatan bukaan MV bertujuan agar terjadi penurunan tekanan steam product menuju nilai SV dengan cara membuang steam melalui steam vent silencer. Jika tekanan yang dikehendaki masih dibawah nilai SV, maka persentase bukaan MV menurun agar tekanan steam product masih bisa meningkat sesuai SV dengan cara mengurangi steam yang terbuang menuju steam vent silencer. 
Sementara itu, hasil pengujian digital control dilakukan pada bagian MOV610, hasilnya dapat ditunjukkan melalui Tabel 16. Hasil pengujian digital control menunjukkan respon dalam dua kondisi, yaitu on dan off telah sesuai dengan command yang diberikan.

Tabel 16. Hasil Pengujian Digital Control MOV610

\begin{tabular}{cccc}
\hline $\begin{array}{c}\text { Pengujian } \\
\text { ke- }\end{array}$ & Command & Warna objek MOV610 & Respon \\
\hline 1 & MOV610 on & Merah & MOV610 on \\
2 & MOV610 off & Abu-abu & MOV610 off \\
\hline
\end{tabular}

\section{KESIMPULAN}

Simulasi kendali Boiler B-1102 PT.Petrokimia Gresik pada sistem Steam \& Feed Water berbasis DCS dengan bantuan fitur test function pada software Centum VP berhasil dibuat dengan dua tampilan Human Machine Interface (HMI), berupa Main window dan Trend window. Program simulasi berhasil diuji dengan pengujian indicator, analog control, dan digital control. Hasil pengujian indicator menunjukkan nilai output pada HMI bernilai sama dengan nilai input yang diberikan. Hasil pengujian analog control dengan SV konstan dapat diamati melalui perubahan nilai bukaan control valve sebagai nilai MV terhadap perubahan nilai PV, serta dapat diamati responnya terhadap waktu melalui trend. Hasil pengujian digital control menghasilkan aksi sama dengan command yang diberikan pada kondisi on dan off. Simulasi berjalan sesuai dengan skenario proses kerja sistem pada kondisi operasi normal.

\section{DAFTAR PUSTAKA}

Alvionita, D. (2018). Simulasi Modifikasi Plant pada Coarse Hydrate Precipitation Menggunakan Panel Simulator DCS Centum VP. Yogyakarta: STTN-BATAN.

Begum, K. G., Mercy, D. \& Vedi, H. K. R. M. (2013). An Intelligent Model Based Level Control of Boiler Drum. International Journal of Emerging Technology and Advanced Engineering, III(1), 516-521.

Bolton, W. (2006). Sistem Instrumentasi dan Sistem Kontrol. Jakarta: Erlangga.

Mardlijah, M. S. \& Mudjiati, T. (2016). Desain Sistem Kendali Temperatur Uap Superheater dengan Metode Fuzzy Sliding Mode Control. Journal of Mathematics and Its Application, XIII(1), 37-48.

Maulida, M., Ekawati, E. \& Samsi, A. (2013). Pembuatan Operator Training Simulator Unit Metanasi Parik Amonia Menggunakan DCS Centum CS3000 Yokogawa. Jurnal Otomasi, Kontrol dan Instrumentasi, V(2), 83-89.

Nashriyah, R. (2017). Pembuatan Simulator Reaktor Kartini Berbasis Centum VP dengan DCS Simulator Panel. Yogyakarta: STTN-BATAN.

Training Division Service Department. (2007). Centum VP Engineering Course. Jakarta : PT. Yokogawa Indonesia. 